\title{
Open Source Seeds and the Revitalization of Local Knowledge
}

\author{
Martin Fredriksson (D)
}

check for

updates

Citation: Fredriksson, M. Open Source Seeds and the Revitalization of Local Knowledge. Sustainability 2021, 13, 12270. https://doi.org/ $10.3390 /$ su132112270

Academic Editor: Asterios Bakolas

Received: 22 August 2021

Accepted: 28 October 2021

Published: 6 November 2021

Publisher's Note: MDPI stays neutral with regard to jurisdictional claims in published maps and institutional affiliations.

Copyright: (C) 2021 by the author. Licensee MDPI, Basel, Switzerland. This article is an open access article distributed under the terms and conditions of the Creative Commons Attribution (CC BY) license (https:// creativecommons.org/licenses/by/ $4.0 /)$.
Department for Culture and Society, Linköping University, SE-581 83 Linköping, Sweden; martin.fredriksson@liu.se

\begin{abstract}
This article engages with the resistance against the global erosion of seed diversity following the modernization and industrialization of agriculture over the 20th century. This resistance spans from local farming communities that preserve and safeguard traditional landraces to international movements which oppose proprietary seed regulations and promote free sharing of seeds. The article focuses on the latter and presents a study of the open source seed movement: an initiative to apply strategies from the open source software movement to ensure the free circulation of seeds. The erosion of seed diversity can be seen not only as a loss of genetic diversity but also a memory loss where traditional, collective knowledge about how to grow certain landraces is forgotten. Consequently, the open source seed movement is not only about saving seeds but also about preserving and revitalizing local and traditional ecological knowledge against privatization and enclosure through intellectual property rights. The aim of this article is, thus, to analyze the open source seed movement as an act of revitalization in relation to intellectual property rights and in the context of information politics.
\end{abstract}

Keywords: open source seeds; commons; intellectual property rights

\section{Introduction}

They please me as a farmer, they please my community, they've become part of our social fabric and they integrate really well with the soil and the bugs. And that's when I start calling them a 'landrace' - when they're really part of me and part of my farm.

Joseph Lofthouse, Free the seeds, S2 E2

In the podcast Free the seeds, Utah farmer Joseph Lofthouse speaks of his attempts to develop modern landrace muskmelons. The term landrace usually refers to old seed varieties that have been grown by local farmers over generations. While Lofthouse is indeed dedicated to preserving such traditional landraces [1], he also embraces the concept of modern landraces. Lofthouse defines a modern landrace not through its legacy but through its integration with the local soil, the social context and the farmers who inhabit it. Lofthouse speaks of how seeds and plant varieties are part of a complex interrelation between ecological environment, social fabric and individual identities, and he concludes that 'part of being a landrace is becoming part of the community'. In that sense, his view on seeds resembles the approach [2] (p. 7) takes in an anthropological study of seed saving where she argues that 'Seeds, like people and other non humans, have histories that condition their existences and their present embodiments suggest their possible futures. Visible or not, seeds exist as part of plants, as potential food, as governed being'. This article explores how farmers like Lofthouse relate to seeds and ecological knowledge as governed beings and as part of a social and ecological context and community.

Free the Seeds is a series of podcasts produced and published by the organization Open Source Seed Initiative, consisting of interviews with farmers and breeders who are committed to so-called open source seeds. The Open Source Seed Initiative was founded in USA in 2012 and is part of a wider open source seed movement, which attempts to apply the ethical and legal rationale of open source software licensing to seeds in order to enable the free sharing of seeds in the face of restrictions imposed by intellectual property rights. 
The commitment of Joseph Lofthouse and his fellow open source seed breeders is a reaction against how industrialized seed breeding contributes to the loss of biological diversity by globally promoting a small range of seed varieties that lead farmers to abandon local varieties. As this depletion of biodiversity is exacerbated by intellectual property rights that allow large commercial seed breeders to dominate the market and dictate conditions for local farmers, the Open Source Seed Initiative has taken an intellectual property approach to biodiversity and seed sharing.

Applying open source licenses to seeds is a novel strategy to address an urgent environmental challenge that is hitherto highly under-researched. The open source seed movement thus warrants more scholarly attention as a social and environmental intervention. This article is a contribution to that, still scarce, body of knowledge aiming to understand the contemporary role and future potential of the open source seed strategy in the struggle to promote biodiversity. Unlike previous studies on the topic, it particularly explores the interconnections between the discourse on seed sustainability and the information commons movement.

Lofthouse's reference to landraces highlights how the depletion of seed diversity also involves the loss of traditional and local seed varieties that are going extinct as mass produced commercial varieties take over. In another article in this special issue of Sustainability, [3] discuss the struggle to preserve such landraces and maintain the traditional knowledge of how to grow them as acts of revitalization. The term revitalization was originally coined by Anthony Wallace in the 1950s to refer to systemic attempts to recreate society into a new 'more satisfying culture' [4] (p. 256). Since then, the term has however predominantly been used by anthropologists to describe more particular acts of revitalization where marginalized communities try to reconnect to their traditions by reviving old practices that have been ignored or suppressed under modernization. Such acts span from reintroducing traditional foodstuff, through traditional arts and crafts to preserving Indigenous and local languages that risk becoming extinct. Revitalization can thus both have a particular and a systematic meaning, depending on if it refers to the revival of specific practices or of reformation of social and cultural structures [3].

While the concept of revitalization is most often evoked in relation to cultural continuity it can also be related to ecologic sustainability since many revitalization practices concern the reinterpretation and reintroduction of traditional ways to manage natural resources that are better adapted to the local conditions and thus more ecologically and socially sustainable. The preservation and revival of traditional landraces is one example where revitalization and sustainability intersect, and environmental conservation overlaps with the preservation of traditional knowledge and practices. In that regard, revitalization movements are often a reaction against how the 'homogenizing forces of modernity' threaten local diversity [3]. Since this erosion of seed diversity can be seen not only as a loss of genetic diversity but also a memory loss where traditional, collective knowledge about how to grow certain landraces is forgotten, such seed sharing initiatives are also a kind of collective knowledge community that preserves seeds as well as traditional knowledge passed on from previous generations [3]. The concept of revitalization thus provides a perspective that allows me to approach the open source seed movement both as a social and an environmental initiative, acknowledging the importance of promoting biodiversity and the free sharing of information alike.

\section{Questions, Materials and Methods}

This article approaches the open source seed movement from an information political perspective, contextualized in relation to a discourse on revitalization. It relates the conflicts and contestations over the control and circulation of seeds to a discourse on the control and sharing of information and explores how the open source seed movement's approach to seed diversity and the free sharing of seeds draws on rhetoric and strategies developed within an information commons movement that emerged in the 1990s to protect the free sharing of knowledge and information against an expansive copyright regime. The article 
explores the following research questions: Are there similarities between the open source seed movement and the information commons movement? To what extent can approaches from the open source movement be applied to promote biodiversity and the free sharing of seeds? Can the open source seed movement be seen as a form of revitalization movement, and if so, what is being revitalized?

Methodologically, the article relies on a close reading of the development of the open source seed movement and a theoretical contextualization that interprets that development from a revitalization and information commons perspective. First, it constructs an overview of the formation, goal and strategy of the open source seed movement, based on three different kinds of sources. It partly uses primary sources such as the text of the seed license itself, mission statements, websites and podcasts from the organization and journalistic news reports featuring interviews with members of the movement [5]. It also relies on a limited body of existing research that can be divided into two sections. Most academic publications about the open source seed movement have been written by active members of the movement who have, sometimes, also taken part in developing those licenses (most importantly Jack Kloppenburg and Claire Luby in the USA and Johannes Kotschi in Germany). This material can be seen as a hybrid between empirical sources and secondary research, and it tends to focus on defining the problem of seed enclosure through intellectual property rights and analyzing the possibilities of addressing that problem through the promotion of an open source seed approach [6-14]. There are, furthermore, a very limited number of studies that address the open source seed movement from the outside, analyzing the legal implications of the licenses $[15,16]$ or the social and political significance of the movement [1,17-19]. The overview of the open source seed movement is thus based on a kind of narrative literature review where the results from previous studies are interfolded in an analytical narrative about the formation and character of the movement (presented in Sections 3 and 4). The existing scholarly literature on the open source seed movement is so scarce that I have been able to make an exhaustive literature overview including all academic work published on that specific topic up to date. This literature provides the data that the overview of the open source seed movement presented in Chapter 3.4 relies on.

The results from the literature review are analyzed in relation to existing research on the enclosure of the information commons. The wider field of research on the information commons is, on the other hand, far too expansive to allow for a comprehensive and inclusive overview. Instead, this article draws on a synthesis of existing research fields that address the question of information commons more or less explicitly. One such strand of research on the information commons (or knowledge commons as it is sometimes called) departs from the groundbreaking work of Elinor Ostrom [20] on Governing the Commons. This work is predominantly engaged with applying the methodological framework that Ostrom and her followers developed to analyze different modes of sharing material resources as commons, to better understand the sharing and managing of information [21,22] (c.f. Sievers-Glotzbach et al. [17] who apply this perspective to seed commons). Another, much larger strand of information commons research focusses on the intersection between (predominantly digital) technology and intellectual property rights (primarily copyright). This work dates back to the 1990s and the seminal work of intellectual property scholars such as James Boyle [23], Lawrence Lessig [24], Roland Bettig [25] and Rosemary Coombe [26]. Although most of these researchers do not explicitly use the term information commons, they focus on the potential conflicts between new technologies' capability to contribute to a wider dissemination of culture and information as a commonly shared resource, and the attempts to curtail those possibilities in the name of protecting intellectual property rights in the digital age. Over time, this grew into what can be described as a field of critical IPR studies, addressing how the extension and globalization of intellectual property rights in general, and copyright in particular, threaten the information commons [27-45]. This field of research has also come to inspire a heterogeneous activist movement protecting freedom of information against the expansion of intellectual property rights (see Fredriksson [37] 
for a discussion on the relation between critical copyright research and the information commons movement).

The primary result of the study thus consists in describing and contextualizing the open source seed movement based on the publications of the organizations themselves compared to existing research on the information commons movement. Consequently, the article begins with an overview of how modern seed legislation has affected biodiversity and farmers' rights to save and share seeds, and how this relates to the regulation and commodification of knowledge and information in general. This is followed by a closer account of the development and approach of the American organization Open Source Seed Initiative and its European counterpart Open Source Seeds. Finally, it concludes with a theoretical discussion and analysis that relates the open source seed movement to a wider information commons movement as well as to a revitalization perspective.

\section{Results}

\subsection{Global Seed Regulations and the Emergence of the Global Seed Market}

Over the 20th century, global agriculture transformed from a seed supply system based on the farmers' own seed production and informal systems of seed exchange, to the centralized and regulated seed system of today [19]. Modern scientific plant breeding-where plant varieties are developed by scientists at research facilities rather than by practicing farmers-first emerged in Germany in the 1860s, but caught speed at the turn of the century [13]. These new scientific methods of plant breeding produced more high-yielding and pest-resistant crop varieties that contributed to a sharp increase in agricultural production [14]. By the late 19th century, a system of governance had been set up in Eastern Germany where institutions tested and registered new seed varieties to ensure the quality of the seeds. In parallel to this, a commercial seed market evolved and it became possible to claim exclusive rights to seed varieties by different legal means $[14,46]$.

Throughout the 20th century, countries all over the world passed laws to control the distribution of seeds. The main aim of such seed legislation was, initially, to prevent the distribution of poor quality seed, but stricter regulations also gave seed companies the opportunity to increase the use of certified, commercially distributed proprietary seed [14]. As early as 1930, the American Plant Patent Act made it possible to patent plant varieties in the USA [46]. Internationally, protection for plant varieties has primarily been ensured through so-called plant variety protection legislation which gives plant breeders a property right, similar to that of patents, to the germplasm-i.e., the genetic information-of the seeds they develop [46]. While plant variety protection laws were passed nationally across Europe and North America in the 1960s and 1970s, there was also a development towards international harmonization of plant variety protection laws, primarily driven by the International Union for the Protection of New Varieties of Plants (UPOV). UPOV was founded in 1961 and the UPOV Convention to coordinate the protection of plant varieties came into force in 1968 [46]. The internationalization of plant variety protection entered a new phase with the passing of the agreement of the Trade Related Aspects of Intellectual Property (TRIPS) as one of the pillars in the newly formed World Trade Organization in 1994. Since article 27.3 of the TRIPS agreement requires all member states to provide some form of intellectual property protection for plant varieties, the principle of plant variety protection is now globally enforced [9,10,16,19,46-48].

Modern plant breeding has indeed provided new varieties with increased germination ability and resistance to diseases [14]. This has, however, been at the cost of a strong decrease in crop biodiversity since the seed legislation privileges large-scale, industrialized seed development. To be approved for commercial exchange, a new seed variety must meet the so-called DUS criteria, meaning that it must be distinct, uniform and stable in its characteristics. While industrially produced varieties easily meet those standards, many local varieties do not $[17,49]$. Peschard and Randeria argue that: 
Farmer-selected varieties, by contrast, are genetically unstable, which is precisely what makes them highly adaptable to specific soils and cultivation systems, and are adapted to low-input farming. However, because they do not meet commercial criteria, peasant varieties are often no longer considered seeds, under a country's seed legislation, but 'grains' and cannot circulate legally. [49]

Seed regulations thus impose a distinction between industrially produced seeds and local varieties which have been developed and shared by small-scale farmers. These regulations hamper the distribution of local varieties and promote a limited number of globally marketed varieties that are stable, homogenous and respond well to pesticides, but are less adapted to the local growing conditions than many landraces and farmer-selected varieties $[19,49,50]$.

The dominance of a small range of industrially produced seeds has provoked resistance from a wide range of farmers' movements, and social rights activists have accused the seed industry of imposing a neo-colonial property regime that subjects farmers of the global south to exploitation from multinational corporations [51]. Furthermore, the narrative of plant breeding as the endeavor of Western scientists also discards a much longer history of agricultural knowledge production that has taken place beyond the borders of the colonial empires. There are indeed plenty of examples of how Indigenous people across the world have actively managed and developed local seed varieties long before the colonial settlers arrived [46,51,52]. The regulation of seeds is thus not only a matter of agricultural politics; it is also entrenched in global, postcolonial knowledge politics. Departing from that realization, this article sets out to contextualize the commodification of seeds in relation to the commodification and control of knowledge in a global, postcolonial information economy.

\subsection{Seeds, Information and the Second Enclosure}

Ontologically speaking, a seed is a complicated matter. Sievers-Glotzbach et al. [17] (p. 420) argue that 'a complex interrelation exists between the material seed (the reproductive entity of a plant) and its role as the carrier of genetic information applicable to the variety (immaterial component)'. As 'material planting resources', seeds can, potentially, be used in various ways: they can be planted, reproduced, replanted, saved, shared or manipulated to breed new varieties [17] (p. 420). The regulations that apply to the genetic information the seeds carry, nevertheless, prohibit this. Defining seeds as intellectual property is fundamental to the growth of the seed industry since intellectual property can be commodified in a different manner than material goods. Subjecting seeds to intellectual property rights has given the seed companies control over how the seeds are used and circulated after sales. Turning seeds into intellectual property can be seen as a process of dispossession where farmers have, as Aoki [16] (p. 2275) astutely puts it, been reduced 'into consumers providing labor to raise crops in which others hold the underlying intellectual property rights'.

The fact that the farmers who buy the material seed do not own the intellectual property-the germplasm - it embodies, allows the seed companies to impose terms of use that prohibit farmers from reproducing seeds or sharing them with neighbors and colleagues [2]. Peschard and Randeria [49] (p. 615) reflect on how this has changed the use of seeds:

For most of agricultural history, seeds have been freely (re)produced and exchanged by farmers. This is because an intrinsic characteristic of the seed-the capacity to reproduce itself-acted as a built-in barrier to capital accumulation. [... ] the radical change brought about through the introduction of agricultural biotechnology-first hybrid seeds, and more recently genetically engineered seeds - is that it allowed capital to overcome social and biological barriers to the capitalization of agriculture by constraining farmers' ability to save seeds. The introduction of biotech crops in the mid-1990s was accompanied by a draconian proprietary rights system that includes patents, private licensing contracts en- 
tered into upon the purchase of seeds, and the corporate surveillance of farmers to ensure enforcement of these contracts. As a result, not only are farmers legally prohibited from saving and replanting biotech seeds, they no longer even own the seeds.

This shows how law and technology interact in constructing seeds as a form of intellectual property that can be commodified in an entirely different capacity and on a larger scale than if they were to be traded as merely material commodities. Peschard and Randeria [49] point to the well-known, dire consequences this property regime has for small-scale farmers' possibilities to use the seeds they buy in a sustainable way. There are plenty of infamous examples where farmers have been heavily fined for violating those terms of use, sometimes unwillingly and unknowingly due to random cross fertilization with licensed seed from neighboring farms $[2,19,49,50,53,54]$.

In the 1990s, a combination of improved technologies for genetic engineering and stronger plant variety protection legislation made the seed industry even more profitable. This led to a restructuring and integration of the seed industry on three levels: horizontal, with the merging of seed companies; vertical, with the integration of companies at different levels in the chain of production and distribution; and global, where multinational companies expanded into new markets $[2,16,19,49,50]$. This market concentration contributed further to the depletion of seed diversity since the companies tended to reduce their portfolios of seed varieties after merging [12]. In that regard, the seed industry followed the same development towards globalization and concentration of ownership that characterized many other industries in the 1980s and 1990s. This was not the least case with the media sector where the dominance of the large media houses contributed to a similar homogenization of the global selection of media content $[45,55]$. Just like the seed companies, the media houses and other intellectual-property-based businesses profited greatly as intellectual property became an increasingly valuable form of assets in the growing information economy.

While copyright and patent laws have existed since the 18th century, the 1990s saw a rapid expansion of intellectual property rights to support the growing content-based industries. Knowledge, information and creative works were protected by an expanding suite of intellectual property rights tailored to promote the commodification of information in a digital environment, and homogenized and enforced globally through international treatises like the TRIPS agreement $[35,45]$. The fact that the TRIPS agreement is one of the cornerstones of the WTO gave intellectual property rights a new role in international politics and economics. This 'relocation of intellectual property law within the WTO system' is, as Fiona MacMillan puts it, 'an acknowledgement of the ever-increasing significance of intellectual property rights in international trade and investment' [37] (p. 13). At the hands of the WTO, intellectual property rights are enforced more forcefully as protection of economic investments than as a tool for social or cultural development $[34,35]$. With the economization of intellectual property rights in the 1990s, contestations over intellectual property violations also took center stage in international relations where corporations, politicians and trade representatives from Europe and North America intensified their campaigns against piracy in the global South [44,56]. Particularly, China and India drew attention from American trade representatives who targeted China as a haven for international media piracy and counterfeits of fashion brands and accused India's generic pharmaceutical industry of violating international patent regulations $[57,58]$.

The 1990s thus saw the expansion of intellectual property rights in at least two regards. In one regard, an escalation of economic globalization called for stronger implementation of intellectual property rights in emerging economies, which was often criticized as a new phase of neo-colonial exploitation. Parallel to this, intellectual property laws came to apply to a wider range of resources (such as genetic information) and forms of distribution (most importantly, digital distribution). This was widely recognized as a neoliberal process of privatization that limits public access to culture and information, both in the developing and the developed world. 
Already in the 1980s, the tech visionary Stewart Brand [59] (p. 202) coined what would become a tagline for the information commons movement: 'Information wants to be free'. However, he continued to acknowledge that "Information also wants to be expensive. Information wants to be free because it has become so cheap to distribute, copy, and recombine-too cheap to meter. It wants to be expensive because it can be immeasurably valuable to the recipient". This tension, where a resource is on the one hand inherently free to share and distribute, but on the other hand potentially valuable on the conditions that that freedom is curtailed, also marks the distribution of seeds. The fact that both information and seeds are capable of reproducing themselves at no cost makes it necessary to develop laws and techniques that can limit that capacity in order to make it possible to trade them as commodities. Peschard and Randeria's [49] description of how technologies and legal regimes are employed to curtail the natural reproductive capacities of seeds also corresponds to the common critique against the copyright regime for imposing an 'artificial scarcity' on information: a resource that is inherently, infinitely reproducible [43]. This artificial scarcity is a prerequisite for the commodification of information, just as the restrictions of the seeds' reproductive capacities enables a further commodification of seeds under an intellectual property rights regime.

Critical theorists and copyright scholars have argued that protecting ever wider ranges of information and genetic resources as property that can be bought and sold is part of a continuous effort to extend the boundaries of property and privatize resources that used to be free and publicly accessible [23,25,28,30,35,42,43,45,60-62]. In the copyright debates, the propertization and privatization of a growing range of previously common resources, from information and cultural heritage to traditional knowledge and genetic resources, has been conceptualized as a second enclosure movement $[24,27,28]$. The term refers to the historical enclosure of agricultural land in England between the 15th and 19th centuries, when land areas that had been collectively used were gradually fenced in and placed under the exclusive control of wealthy landowners [27,63]. While some historians see the enclosure of the commons as a necessary introduction of more efficient means of managing farmland, others see it as depriving poor people of their means of support and disrupting the fabric of society for local rural communities [63]. In his seminal article 'The Second enclosure movement and the construction of the public domain', James Boyle [27] (p. 35) describes the first enclosure movement as 'the loss of a form of life' when 'the relentless power of market logic to migrate to new areas' disrupted 'traditional social relationships and perhaps even views of the self or the relationship of human beings to the environment'.

Boyle [27] (p. 36) goes on to draw parallels to present day expansion of intellectual property rights:

We are in the middle of a second enclosure movement. It sounds grandiloquent to call it 'the enclosure of the intangible commons of the mind,' but in a very real sense that is just what it is. True, the new state-created property rights may be 'intellectual' rather than 'real,' but once again things that were formerly thought of as either common property or uncommodifiable are being covered with new, or newly extended, property rights.

By speaking of a second enclosure process, Boyle conceptualized the privatization of culture and information through intellectual property as analogous to the enclosure of public space and natural resources. Boyle was indeed not the first to make this analogy, as he himself willingly acknowledges that a number of other copyright scholars had employed that metaphor before him [27] (note 12); c.f Travis [64]. Just as with the first enclosure movement, proponents of strong property rights claim that expansion and stronger protection of private property ensure a more efficient use and commercialization of resources, while their opponents argue that the expansion of intellectual property rights restricts a wide range of uses that have previously been tolerated and that serve social and cultural purposes for different communities. 


\subsection{Seed Activism and the Information Commons Movement}

A similar enclosure of the seed commons-where seeds are being subjected to property regimes that prevent them from being shared freely-has been resisted, both globally and locally, by various social movements. This resistance spans from ideologically motivated international environmental and social rights organizations to local farming initiatives that preserve and safeguard local varieties and traditional landraces. Karine Peschard and Shalini Randeria [50] trace the discourse on farmers' rights to the 1980s when activists began arguing that the farmers' rights to freely save and share seeds should be recognized on equal footing with breeders' rights to protection of their intellectual property. While plant breeders' rights generally only apply to new seed varieties produced by professional, scientific breeders, farmers' rights acknowledge that farmers have been managing and developing landraces for generations and that they are entitled to recognition for that, both as individual authors and as collective custodians. The idea of farmers' rights reflects a different epistemology about seeds as it acknowledges that seeds are not only developed in research facilities run by universities and corporations but that local farmers and Indigenous communities have contributed greatly to the developments of seeds, since the 'primitive' germplasm collected in the biodiversity-rich developing countries had in many cases been bred and improved by Indigenous people over generations. This germplasm is, as Kloppenburg [46] (p. 186) puts it, 'not a free gift of nature, but is the product of millions and millions of hours of human labor'.

Since the 1980s a number of NGOs and activist groups across the world have been lobbying for an acknowledgement of farmers' rights within the international community, and primarily the United Nations Food and Agriculture Organization (FAO). Some advances have also been made. In 1989, the FAO Resolution 5/89 endorsed farmers' rights as the 'rights arising from the past, present and future contributions of farmers in conserving, improving, and making available plant genetic resources, particularly those in the centers of origin/diversity' [49]. Twelve years later, the 2001 International Treaty on Plant Genetic Resources for Food and Agriculture marked another landmark for the farmers' rights movement as it finally recognized farmers' rights to the protection of traditional knowledge as well as to participation in decisions regarding the exploitation of plant genetic resources and shares of the benefits they create [49].

Many farmers' rights activists nevertheless discard the inclusion of farmers' rights in the Seed treaty as a marginal concession that merely legitimizes the continuous propertization and theft of seeds from Indigenous people and farmer communities of the global south [49]. A profound imbalance between the regulation of farmers' rights and plant breeders' rights certainly persists: while farmers' rights are still marginal, plant breeders' rights have been entrenched in global trade regulations for decades. This imbalance between proprietary rights and the rights of users applies across all aspects of intellectual property rights: while there is a rich body of laws protecting information as property, there is no legislation, internationally or nationally, protecting information as a commons [34]. Even though copyright law, just like plant variety protection, indeed includes exceptions that allow the free use of protected works under certain circumstances, international legislation on intellectual property rights tends to focus more on enforcing rights of ownership than use. Consequently, the internationalization of intellectual property rights since the 1990s has been accused of pushing the balance from users' rights to owners' rights [37].

This enclosure of the information commons has provoked the mobilization of a wider information commons movement involving actors ranging from the Pirate Party, which made an impact in parliamentary elections all over Europe around 2010, to advocacy groups like Electronic Frontier Foundation and underground hacker networks such as Anonymous [36,37]. While these organizations rely on different methods and organizational models, they all aim to promote and protect the free sharing of information against expansive intellectual property regimes. They embrace the belief that digital technologies have the potential to create new ways of sharing culture, knowledge and information, all to the benefit of public education and democratic participation, but that these possibilities 
are being curtailed by extensive use of copyright and patents [39]. Just like farmers who were prevented from saving and sharing seeds by restrictive plant variety protection, the information commons movement was thus provoked by how intellectual property rights undermined the practical possibilities to use the resources-be it information or seeds-to their full potential.

\subsection{The Development of the Open Source Seed Movement}

If the commodification of seeds as information was enabled by intellectual property rights, it is congenial that the resistance against the commodification of seeds would eventually borrow strategies and rhetoric from other movements opposing the expansion of intellectual property rights. The open source seed movement, which attempts to apply the legal and epistemological framework of open source software programming on agriculture by subjecting seed varieties to open source licenses, is maybe the most obvious example of this. As already mentioned, most of the writing on the open source seed movement has been undertaken by the members themselves, documenting the movement or presenting and analyzing its legal and political approaches. A cross reading of this material against the few existing studies of the open source seed movement presents a significantly coherent narrative about the formation and strategy of the open source seed movement, which will be presented in this section.

Kotschi and Rapf [13] (p. 13) describe the idea of open source licenses for seeds as a solution to protect seeds 'as a common good', in times 'when the legal basis for securing private property appears overwhelming and while commons hardly enjoy any legal protection'. In this regard, the same imbalance between strong protection for the rights of owners versus very scarce protection for users' rights applies both to knowledge and information and to seeds and germplasm [12].

The open source seed movement differs from most other farmers' rights organizations in the sense that it initially emerged among university-employed scientists in the Western world. The first open source seed organization, the Open Source Seed Initiative (OSSI) was formed in USA in 2012 by Jim Meyers, professor of genetics at Oregon State University, Irwin Goldman, professor at the University of Wisconsin and the independent plant breeder Frank Morton in Oregon [5]. Soon Jack Kloppenburg, sociologist and author of the seminal book on the history of seed regulations, First the Seed [46], joined in. Meyers, Goldman and Morton had all experienced how commercial plant breeders patented plants containing germplasm based on varieties they had themselves been developing for years, with the consequence that they could no longer continue developing these varieties. Since this was a common problem for many independent or university-employed plant breeders, they founded the Open Source Seed Initiative with the goal of defending and promoting the free sharing of seeds as an open source resource. Within a year, the network comprised more than 20 members, mostly scientists and plant breeders from different American universities [5,9]. Within a few years, the circle would expand and by 2017 the American open source seed movement largely consisted of freelance, independent breeders, such as Joseph Lofthouse [1,9].

The idea of open source seeds had however circulated for a while. Already in the late 1990s, Tom Michaels, horticulturalist at the University of Minnesota, had been toying with the idea of applying open source licenses to seeds to keep them freely accessible to the breeding community. The idea was directly inspired by Michaels' son who was a dedicated open source programmer $[1,5]$. Open source software traces its origins back to the copyleft license that was developed and widely promoted by the programmer and digital rights activist Richard Stallman in the 1980s [8]. Copyleft or open source licenses for software were a reaction against how copyright law gave copyright holders exclusive rights to prevent other programmer from developing that code. Merely abstaining from claiming copyright to the software one created was however not a solution since that would allow someone else to modify and claim the rights to that code. Open source licenses, on the other hand, retain the copyright of the programmer, but release the source code 
under a license agreement that allows the code to be used freely by anyone, but prohibits users from appropriating and restricting another programmer's use of an application that includes parts of that source code. That way, open source programmers could collaborate on various projects and share code freely without having to fear that the code would be appropriated and their future use of that code restricted. These ideas gained wider traction in the 1990s, culminating in the formation of the Open Source Initiative in 1998 [19,65]. Since then, the copyleft principles, that anyone is free to use a shared resource but no one is allowed to restrict other people's use of it, have been applied in many different ways. The copyleft application that has been most important for public access to knowledge and culture is probably the Creative Commons license, initiated by law professor Lawrence Lessig in 2001, and adapted to enable a free and sustainable circulation of creative and scientific works in open access $[8,24,65]$.

In the end, the OSSI collective, however, came to the conclusion that open source licensing was not immediately applicable to seeds since the ownership of code and germplasm are controlled as different forms of intellectual property. Open source licenses on software are enabled by the fact that software is copyright protected: this means that software code automatically becomes the property of the author the moment it is created, which makes it possible for the copyright holder to distribute it under a copyright license. Doing the same thing with plant varieties would require the breeders to first go through the hurdles of (and overcome the ideological resistance to) patenting it and then formulating a legally and technically comprehensive licensing agreement that could fit onto a seed package $[1,5,10,24]$. One could say that open source license on source code is a way of giving away a property right that is forced upon the programmer, while open source license on seeds would require the breeder to first claim that right in order to give it away.

Eventually OSSI gave up the idea of enforcing open source seeds with legal means; instead they chose a public relations route. They developed the so-called OSSI pledge: a text printed on the packet of all OSSI-certified seed stating that 'You have the freedom to use these OSSI-Pledged seeds in any way you choose. In return, you pledge not to restrict others' use of these seeds or their derivatives by patents or other means, and to include this pledge with any transfer of these seeds or their derivatives.' [11] (p. 4) (https://osseeds.org/ accessed on 27 October 2021). The text is mapped on the shrink wrap licenses that accompany proprietary seeds, but while the proprietary licenses restrict the rights to use the seeds, the OSSI pledge begs its users not to restrict other people's use of the seed. Unlike copyleft licenses, the OSSI pledge is thus not a legally binding text but merely a plea of good will. In that sense the focus shifted from a legal hack to awareness raising and community building. Drawing on E.P Thompson, Maywa Montenegro de Wit [1] (p. 58) describes the OSSI switch from legal licenses to ideological pledge as a move towards emphasizing the 'moral economy' of the commons. Luby et al. [9] on the other hand characterizes it as creating an 'open source brand', comparable to the well-established fair trade brand [9] (p. 285), [10,18]. Currently, 38 plant breeders are part of the OSSI network and more than 400 seed varieties have been released under the OSSI pledge (https: / / osseeds.org/ accessed on 27 October 2021).

The Open Source Seed Initiative soon gained attention in Europe, and in 2017 a German counterpart, Open Source Seeds, and its associated organization, the German organization Association for AgriCulture and Ecology (Agrecol) were formed (https: / / opensourceseeds. org / en/about-us accessed on 27 October 2021). The OSSI framework could not, however, be seamlessly transposed from America to Europe since the legal framework differs in certain significant regards. In America it has been common practice to patent plant varieties ever since the passing of the Plant Patent Act in 1930 [5,46]. Seed patents are much less common in Europe where plant varieties are predominantly protected under plant variety protection. Furthermore, unlike the USA, Germany and the rest of the EU have ratified the Convention of Biological Diversity and the Nagoya protocol on Access to Genetic Resources and the Fair and Equitable Sharing of Benefits arising from their Utilization which offers new possibilities to use open source seed licenses [12,15]. 
Considering the different legislative context, Agrecol decided to pursue the legal approach that had been OSSI's initial strategy [15]. At the initiative of Johannes Kotschi and Klaus Rapf, Agrecol set out to create the OSS license (https:/ / www.agrecol.de/ files/OSS Licence_AGRECOL_eng.pdf accessed on 27 October 2021). Technically, this is a Material Transfer Agreement that can be enforced as a contract under German civil law. This transfer agreement requires anyone who uses the seeds to respect the copyleft principles and stipulates that this also applies for future seed variations that utilize the protected germplasm (Open Source License for Seeds, §3.3) [12]. The possibility to enforce that agreement is enhanced by the Nagoya protocol's Access and Benefit Sharing provision which requires anyone who uses a plant genetic resource to document and declare the origins of that resource and, if necessary, prove that it has been acquired and is being used with the consent of the original owner $[12,15,66]$. Originally this provision was developed to protect custodians of traditional ecological knowledge but when applied to recently developed seed the original owner can also apply to local breeders such as the members of the open source seed community [13].

Since it was first initiated in USA in 2012, the open source seed movement has thus developed into a more international and more diverse movement. Apart from its American and European branches, open source seed projects have also been initiated on many continents. In East Africa and India, local organizations are for instance collaborating with the European open source seed organization Hivos to create sustainable business models for growing and sharing open source seeds [12]. Similar initiatives exist in many countries in South America, such as Argentina, where the organization Bioleft is trying to utilize open source strategies to empower local collaborative breeding projects [18]. The open source seed movement is not only active on different continents, but is also applying different strategies, spanning from awareness raising, lobbying and community building to legal enforcement. In an attempt to accommodate this heterogeneity, a Global Coalition of Open Source Seeds Initiative-GOSSI-has been formed to coordinate the collaboration between open source seed initiatives across the world. GOSSI lays down a number of universally applicable core principles that allow for organizations with different methodological and strategic approaches to unite around the common goal of keeping seeds free (https: / / www.opensourceseeds.org/en/gossi\#mission accessed on 27 October 2021). For the moment, the most important dividing line in the open source seed community appears to be that between the American approach of promoting the OSSI pledge and the European strategy of legal enforcement.

The existing literature on the goals and strategies of the open source seed movement reflects a movement still in the making. While it presents a fairly coherent image of the story so far, it does not provide a clear view of where the process is heading. Luby \& Goldman [10] (p. 479) is the only study that looks at actual cases in order to assess how different open source strategies have affected the freedom to use certain breeds, in this case a range of carrot varieties. Their study however did not include any example of open source 'bag-tag licenses' since they found the legal implications of those licenses unclear and never tested in court. As Montenegro de Wit [1] (p. 72) points out, the OSSI pledge is also still untested and its legitimacy is 'largely hypothetical'. The same can be said about the European initiative to reinvent the legal open source seed licenses. It is significant that information about the European seed licenses is primarily to be found in the reports produced by Agrecol itself and none of the existing studies provide a clear response to the question of whether the open source seed licenses that are being launched in Europe could be, or have been, effectively enforced. 


\section{Discussion and Theoretical Context}

The open source seed movement has the declared goal of creating and promoting a 'seed commons' where seeds are protected as a common good that can be shared within a community under specific conditions that prevent them from being withdrawn from the commons and privatized (https://www.opensourceseeds.org/en/about-us accessed on 27 October 2021). As such, it is one example within a broad variety of commons movements that collectively share a resource under agreed upon rules and protocols that guarantee that it is sustainably managed $[20,67]$. Commons in seed sharing systems are generally, as Sievers-Glotzbach et al. [17] (p. 418) put it, a form of 'hybrid commons', that span from 'traditional seed systems (such as seed exchange networks and seed banks) to recent anti enclosure movements [ ... ] that resist intellectual property rights on varieties'. In that regard, the open source seed movement bridges the gap between a global multitude of locally based farmers' rights organization and an international information commons movement.

At first glance, the open source seed movement appears alien to the information commons movement: while the former focuses on soil and seeds, the latter is preoccupied with digital media, and they consequently mobilize different groups. As I have argued in this article, both movements, however, respond to how an expansion of intellectual property rights that has been taking place since the 1990s restricts the uses of previously shared resources. In some regards, the open source seed movement seems to have more in common with the information commons movement than with many other farmers' rights organizations. The open source seed movement, for instance, mobilizes from a radically different position than the farmers' rights movements of the global south. Tsioumani et al. [19] (p. 157) point out that while 'farmer and indigenous communities in particular are usually location-specific' communities, OSSI 'seems to be built on a somewhat artificial community, created specifically in order to oppose IPRs and share seeds.' For the university-employed scientists who were the driving force behind the first mobilization of the predominantly Euro-American open source seed movement, restrictions to use and share seeds are not so much a threat to their livelihood as it is to their ecology of knowledge. With its strong affiliation with academia and its connection to the open source movement, the open source seed movement approaches the sharing of seeds more as a question of free sharing and access to knowledge and information than as a matter of access to the material means of survival.

Anthropologist Gabriella Coleman claims that the open source movement has become a 'legal and collaborative methodology' for different kinds of social movements; a 'pragmatic template by which many other social groups have modeled and directed their endeavors' [68] (p. xxviii). Coleman primarily refers to the hacker movement, but there are plenty of examples of how the open source logics are adapted not only as a metaphor but also as a collaborative philosophy in different digital rights movements; members of the Pirate Party, for instance, sometimes describe it as something like an open source project for politics $[36,40,43]$. OSSI takes this one step further by bringing the metaphor of open source into the field (quite literary) of agriculture.

If the discourse on the second enclosure movement transposes the metaphor of enclosure from land and material resources to culture, information and immaterial resources, then the open source seed movement is an example of the opposite: of how a metaphor and a strategy to regulate the sharing of information can be transposed to land and seeds. The gap between information and environmental politics is not as big as it seems, and the information commons movement has drawn much inspiration from the environmental movement. Alongside its strong legacy within the open source movement, the Pirate Party also frequently compared its own mobilization to the development of the green parties in European politics in the 1980s [39].

Furthermore, knowledge and information have always been a crucial dimension of agriculture, which is evident both in the contemporary discussions on the use and ownership of traditional ecological knowledge and in historical examples. Returning to Boyle's classical thesis, Sean Johnson Andrews [54] (p. 45) argues that Boyle misses the 
fact that the first enclosure movement 'is also the origin of the second' in the sense that it encompassed the enclosure not only of common land but also of 'what we might call the early modern agricultural knowledge commons'. He argues that the scientists and agriculturalists who assisted in the enclosure of English farmland in the 17th and 18th centuries largely relied on knowledge of agricultural methods and techniques that had been developed by local farmers for generations; knowledge that the scientists gathered and compiled to serve the new class of landowners. In that regard, the first enclosure represented 'the accumulation of both land and knowledge into the hands of one class over another' [54] (p. 469). Reflecting on the recent impact of intellectual property rights on the use and distribution of seeds, Johnson Andrews [54] (p. 47) concludes:

We have thus come full circle: we see the first enclosure movement in the second and vice versa, and the contemporary hacker farmer has something in common with medieval poachers and pirates who resisted these impositions by the encroaching capitalist powers bent on the profits of primitive accumulation.

The case of the Open Source Seed Initiative more than anything exemplifies this. By applying the discourse of information commons on seeds and conceptualizing the dominance of proprietary seeds as an enclosure of the seed commons, the metaphor of enclosure is brought back to the land and the realm of agriculture, but infused-possibly revitalized-with a deeper understanding of the politics of information.

Discarding globally distributed, commercial seed varieties in favor of traditional varieties that are better adapted to local conditions is often embraced as a way to promote biodiversity and develop more sustainable modes of food production. These reactions against the seed industry's erosion of seed diversity also involve acts of revitalization where old landraces are reintroduced to safeguard cultural and agricultural heritage. As exemplified in Dahlin and Svensson's [3] case study of the Swedish seed sharing organization Sesam, this interest in traditional landraces highlights how revitalization can be aligned with an interest in local practices and resources as opposed to the homogenizing forces of modernization and globalization.

In the case of the Open Source Seed Initiative, the varieties presented in the Free the Seeds podcast are generally not traditional landraces but new varieties developed by independent breeders. The emphasis is, as Lofthouse expressed in the beginning of this article, not on the heritage of the seed but on its integration in a local context. There is a parallel between how the global design and regulation of seeds does not always align with the local social and ecological conditions, and how the international copyright regime sometimes clashes with the norms and practices for the distribution of media content that apply to local contexts. The information commons movement, for instance, often criticizes international copyright regulations for failing to respect different local regulatory mechanisms such as local protocols for the use of Indigenous traditional knowledge, informal rules for exchange within media markets in the global south $[44,56]$ and specific norms for how to share, distribute and attribute content that exists in many digital forums and social media platforms $[69,70]$. In a similar way, international plant variety protection and the DUS criteria impose universalized standards for distributing seeds that discard local needs and put local varieties at a disadvantage versus internationally certified seed varieties.

Both the open source seed movement and the information commons movement can thus be seen as attempts to revitalize local practices for sustainable use of shared resources that are threatened by globally standardized modes of governance that fail to respect local needs. To return to the opening quote by Lofthouse, the open source seed movement is about promoting seeds that integrate well with the local community: the soil, social context and the practices of individual farmers. The open source seed movement does not focus specifically on revitalizing individual landraces: most of the varieties presented in the Free the seed podcast are not landraces but new varieties, and even Lofthouse's landrace muskmelons are not actually old varieties. These examples are more about revitalizing the practices of developing and sharing local varieties than about maintaining particular varieties from the past. In that sense, the most fundamental rationale of the 
open source seed movement is not to reintroduce practices and seeds from the past into contemporary farming, but to reintegrate contemporary farming practices into the local social and ecological context. This brings us back to Boyle's [27] (p. 35) notion that the first enclosure movement disrupted the 'views of the self and the relationship of human beings to the environment'. The open source seed movement can be seen as an attempt to revitalize that relation by reintegrating seeds, humans and soil in a socioecological context. As Montenegro de Wit [1] (p. 60) argues, by 'revitalizing plant breeding knowledge' the open source seed movement challenges "'long enclosures" of seed knowledge and rights dispossession', representing a 'new ethic of communing seed [ ... ] around which commoning social and economic life can grow'. This also corresponds to how Philips [2] (p. 209) sees seed saving as an ethico-political act that not only saves seeds but also promotes a more sustainable relationship between humans, seeds and their ecological and social environments that 'provides opportunities to review and remake our shared worlds'.

\section{Conclusions and Future Research}

In response to the first two research questions posed in the beginning of this article, I would argue that there are profound similarities between the open source seed movement and the information commons movement in the sense that both are preoccupied with promoting the free sharing of information under threat of being enclosed by expanding intellectual property rights regimes. They nevertheless differ in the sense that they deal with information of different origin that is used in different contexts. The example of OSSI however implies that the legal solutions borrowed from the open source movement have limited applicability to seeds. While open source software licensing can serve as a source of inspiration and as a conceptual template for how to relate to seeds as a shared resource, it is hard to apply as a universal legal solution in the same way as open source licenses have been for software. In response to the second two research questions posed in the beginning of this article, the open source seed movement can certainly be seen as a revitalization movement. It is however more of a systematic than a particular form of revitalization movement since it aims to rewrite and revitalize the rules for owning and sharing nature.

The open source seed movement is still a movement in the making, struggling to come to terms with its different strategic options. This raises a number of environmental, legal, political and philosophical questions. This article has approached a few of them, primarily of a political and philosophical nature, but many questions remain. From a biological perspective it would be interesting to see a comprehensive overview of which kinds of plants and varieties have been protected as open source seeds, and how this contributes to the promotion of biodiversity. A fruitful venue for legal research would be a systematic analysis investigating to what extent the European open source seed licenses are practically enforceable and a case study of if and how they have been successfully employed. Furthermore, it would be interesting to see a comparative analysis of open source seed initiatives in different countries, including not only America and Europe but also initiatives from the global south. Finally, a study of the political significance of the open source seed movement and its impact on national or international legislation and policymaking still remains to be done.

Funding: This research was funded by FORMAS: grant number 2018-02326. The APC was funded by FORMAS: grant number 2018-02326.

Institutional Review Board Statement: Not applicable.

Informed Consent Statement: Not applicable.

Data Availability Statement: Not applicable.

Conflicts of Interest: The author declares no conflict of interest. 


\section{References}

1. De Wit, M.M. Beating the bounds: How does 'open source' become a seed commons? J. Peasant. Stud. 2019, 46, 44-79. [CrossRef]

2. Philips, C. Saving More than Seeds: Practices and Politics of Seed Saving; Routledge: New York, NY, USA; London, UK, 2013.

3. Dahlin, J.; Svensson, E. Revitalizing Traditional Agricultural Practices: Conscious Efforts to Create a More Satisfying Culture. Sustainability 2021, 13, 11424. [CrossRef]

4. Wallace, A.F.C. Revitalization Movements. Am. Anthropol. 1956, 58, 264-281. [CrossRef]

5. Hamilton, L.M. Linux for Lettuce. VQR A Natl. J. Lit. Discuss. 2014, 90. Available online: https://www.vqronline.org/reportingarticles/2014/05/linux-lettuce (accessed on 27 October 2021).

6. Kloppenburg, J. Re-purposing the master's tools: The open source seed initiative and the struggle for seed sovereignty. J. Peasant. Stud. 2014, 41, 1225-1246. [CrossRef]

7. Kloppenburg, J.R.; Chappell, M.J.; Colley, M.; Goldman, I.L.; Luby, C.; Michaels, T.; Morton, F.; Sligh, M.; Stearns, T. Free as in speech, not as in beer: The Open Source Seed Initiative. In Organic Seed Growers Conference Proceedings; Hubbard, K., Ed.; CoOrganic Seed Alliance: Corvallis, OR, USA, 2014; pp. 144-146.

8. Luby, C.H.; Kloppenburg, J.; Michaels, T.E.; Goldman, I.L. Enhancing freedom to operate for plant breeders and farmers through open source plant breeding. Crop. Sci. 2015, 55, 2481-2488. [CrossRef]

9. Luby, C.H.; Kloppenburg, J.R.; Goldman, I.L. Open source plant breeding and the Open Source Seed Initiative. In Plant Breeding Reviews; Janick, J., Ed.; Wiley-Blackwell: Hoboken, NJ, USA, 2016; Volume 40, pp. 271-298. [CrossRef]

10. Luby, C.H.; Goldman, I.L. Improving Freedom to Operate in Carrot Breeding through the Development of Eight Open Source Composite Populations of Carrot (Daucus carota L. var. sativus). Sustainability 2016, 8, 479. [CrossRef]

11. Luby, C.H.; Goldman, I.L. Freeing Crop Genetics through the Open Source Seed Initiative. PLoS Biol. 2016, 14 , e1002441. [CrossRef]

12. Kotschi, J.; Horneburg, B. The Open Source Seed Licence: A novel approach to safeguarding access to plant germplasm. PLoS Biol. 2018, 16, e3000023. [CrossRef]

13. Kotschi, J.; Rapf, K. Liberating Seeds with an Open Source Seed License; Working Paper; AGRECOL: Guggenhausen, Germany, 2016.

14. Kotschi, J.; Wirz, J. Who Pays for Seeds? Thoughts on Financing Organic Plant Breeding, Working Paper, AGRECOL. 2015. Available online: https:/ / opensourceseeds.org/sites/default/files/downloads/Who_pays_for_seeds.pdf (accessed on 27 October 2021).

15. Louwaars, N. Open Source Seed, a Revolution in Breeding or Yet another Attack on the Breeder's Exemption? Front. Plant Sci. 2019, 10, 1127. [CrossRef] [PubMed]

16. Aoki, K. Free seeds, not free beer: Participatory plant breeding, open source seeds, and acknowledging user innovation in agriculture. Fordham Law Rev. 2009, 77, 2275-2310.

17. Sievers-Glotzbach, S.; Tschersich, J.; Gmeiner, N.; Kleim, L.; Ficiciyan, A. Diverse Seeds-Shared Practices: Conceptualizing Seed Commons. Int. J. Common 2020, 14, 418-438. [CrossRef]

18. Cremaschi, A.; van Zwanenberg, P. Bioleft: Open-source seeds for low-input farming systems. J. Fair Trade 2020, 2, 39-43. [CrossRef]

19. Tsioumani, E.; Muzurakis, M.; Ieropoulos, Y.; Tsioumanis, A. Following the Open-Source Trail outside the Digital World: The Case of Open-Source Seeds. TripleC 2016, 14, 145-162. [CrossRef]

20. Ostrom, E. Governing the Commons: The Evolution of Institutions for Collective Action; Cambridge University Press: Cambridge, UK, 1990.

21. Hess, C.; Ostrom, E. (Eds.) Understanding Knowledge as a Commons; MiT Press: Cambridge, MA, USA, 2006.

22. Frischmann, B.M.; Madison, M.J.; Strandburg, K.J. (Eds.) Governing Knowledge Commons; Oxford University Press: Oxford, UK, 2014.

23. Boyle, J. Shamans, Software, and Spleens: Law and the Construction of the Information Society; Harvard University Press: Cambridge/London, UK, 1997.

24. Lessig, L. Code: And Other Laws of Cyberspace; v 2.0; Basic Books: New York, NY, USA, 1999.

25. Bettig, R.V. Copyrighting Culture: The Political Economy of Intellectual Property. In Critical Studies in Communication and in the Cultural Industries; Westview Press: Boulder, CO, USA, 1996.

26. Coombe, R. Cultural Life of Intellectual Properties; Authorship, Appropriation, and the Law, Duke University Press: Durham, NC, USA, 1998.

27. Boyle, J. The Second Enclosure Movement and the Construction of the Public Domain. Law Contemp. Probl. 2003, 66, 33-74. [CrossRef]

28. Boyle, J. The Public Domain: Enclosing the Commons of the Mind; Yale University Press: New Haven, CN, USA, 2008.

29. Lessig, L. The Future of Ideas: The Fate of the Commons in a Connected World; Random House: New York, NY, USA, 2001.

30. Lessig, L. Free Culture: How Big Media Uses Technology and the Law to Lock down Culture and Control Creativity; Penguin Press: New York, NY, 2004.

31. Lessig, L. Remix: Making Art and Commerce Thrive in the Hybrid Economy; Penguin Press: New York, NY, USA, 2008.

32. Vaidhyanathan, S. The Anarchist in the Library: How the Clash between Freedom and Control is Hacking the Real World and Crashing the System; Basic Books: New York, NY, USA, 2004.

33. McLeod, K. Owning Culture: Authorship, Ownership and Intellectual Property; Peter Lang: New York, NY, USA, 2001. 
34. MacMillan, F. Intellectual and Cultural Property: Between Market and Community; Routledge: New York, NY, USA; Abingdon, UK, 2021.

35. Drahos, P.; Braithwaite, J. Information Feudalism: Who Owns the Knowledge Economy? New Press: New York, NY, USA, 2002.

36. Fredriksson, M. The Pirate Party and the Politics of Communication. Int. J. Commun. 2015, 9, 909-924.

37. Fredriksson, M. Information Commons Between Enclosure and Exposure: Regulating Piracy and Privacy in the EU. Int. J. Commons 2020, 14, 494-507. [CrossRef]

38. Fredriksson, M. Sweden and Beyond: The Pirate Party and Non-Media-Centric Media Politics. In Transnational Media: Concepts and Cases; Suman, M., Kern-Stone, R., Eds.; Wiley-Blackwell: Hoboken, NJ, USA, 2019; pp. 191-197.

39. Fredriksson Almqvist, M. Piracy and the Politics of Social Media. Soc. Sci. 2016, 5, 41. [CrossRef]

40. Fredriksson, M.; Arvanitakis, J. Piracy, Property and the Crisis of Democracy. J. Edemocracy Open Gov. 2015, 7, 135-150. [CrossRef]

41. Gillespie, T. Wired Shut: Copyright and the Shape of Digital Culture; MIT Press: Cambridge, MA, USA, 2007.

42. Halbert, D.J. Resisting Intellectual Property Law; Routledge: New York, NY, USA, 2005.

43. Arvanitakis, J.; Fredriksson, M. Commons, Piracy, and the Crisis of Property. Triple C 2016, 14, 132-144. [CrossRef]

44. De Beukelaer, H.; Fredriksson, M. The political economy of intellectual property rights: The paradox of Article 27 exemplified in Ghana. Rev. Afr. Politi- Econ. 2018, 45. [CrossRef]

45. Hemmungs Wirtén, E. No Trespassing: Authorship, Intellectual Property Rights, and the Boundaries of Globalization; University of Toronto Press: Toronto, ON, Canada, 2004.

46. Kloppenburg, J. First the Seed: The Political Economy of Plant Biotechnology, 1492-2000; University of Wisconsin Press: Madison, WI, USA, 2004.

47. Chandra, R. The Cunning of Rights: Law. Life, Bioculture; Oxford University Press: Oxford, UK, 2016.

48. Chandra, R. 'Farmers' Rights in India: “Globally Sui Generis”. Südasien Chron. South Asia Chron. 2016, 6, 119-144.

49. Peschard, K.; Randeria, S. 'Keeping seeds in our hands': The rise of seed activism. J. Peasant. Stud. 2020, 47, 613-647. [CrossRef]

50. Peschard, K.; Randeria, S. Taking Monsanto to Court: Legal Activism around Intellectual Property in Brazil and India. J. Peasant. Stud. 2020, 47, 792-819. [CrossRef]

51. Shiva, V. The Violence of the Green Revolution: Third World Agriculture, Ecology, and Politics; University Press of Kentucky: Lexington, KY, USA, 2016.

52. Pascoe, B. Dark Emu: Aboriginal Australia and the Birth of Agriculture; Scribe Publications: London, UK, 2018.

53. Shiva, V. Biopiracy: The Plunder of Nature and Knowledge; South End Press: Boston, MA, USA, 1997.

54. Johnson, A.S. Property, Sovereignty, Piracy and the Commons: Early Modern Enclosure and the Foundations of the State. In Property, Place and Piracy; Arvanitakis, J., Fredriksson, M., Eds.; Routledge: London, UK, 2017; pp. 36-49.

55. Bagdikian, B.H. The New Media Monopoly; Beacon Press: Boston, MA, USA, 2000.

56. Karaganis, J. (Ed.) Media Piracy in Emerging Economies; Social Science Research Council: New York, NY, USA, 2011.

57. Reddy, T.P.; Chandrashekaran, S. Create, Copy, Disrupt: India's Intellectual Property Dilemmas; Oxford University Press: Oxford, UK; New Delhi, India, 2017.

58. Fredriksson, M. Copyright Culture and Pirate Politics. Cult. Stud. 2014, 28. [CrossRef]

59. Brand, S. The Media Lab: Inventing the Future at M.I.T.; Viking: New York, NY, USA, 1987.

60. Arvanitakis, J. The Cultural Commons of Hope; VDM: Berlin, Germany, 2012.

61. Bollier, D. Silent Theft: The Private Plunder of our Common Wealth; Routledge: New York, NY, USA, 2002.

62. Hardt, M.; Negri, A. Multitude; Penguin Press: New York, NY, USA, 2004.

63. Thompson, E.P. The Making of the English Working Class; Penguin: London, UK, 1963.

64. Travis, H. Pirates of the Information Infrastructure: Blackstonian Copyright and the First Amendment. Berkeley Technol. Law J. 2000, 777, 789-803. [CrossRef]

65. Kelty, C. Two Bits: The Cultural Significance of Free Software; Duke University Press: Durham, UK, 2008.

66. Oberthür, S.; Rosendal, G.K. Global Governance of Genetic Resources: Background and Analytical framework. In Global Governance of Genetic Resources: Access and Benefit Sharing after the Nagoya Protocol; Oberthür, S., Rosendal, G.K., Eds.; Routledge: New York, NY, USA; London, UK, 2014; pp. 1-17.

67. Dahlin, J.; Fredriksson, M. Extracting the Commons. Cult. Stud. 2017, 30, 253-276. [CrossRef]

68. Coleman, G. The Social Construction of Freedom in Free and Open Source Software: Hackers, Ethics and the Liberal Tradition. Ph.D. Thesis, University of Chicago, Chicago, IL, USA, 2015.

69. Bodó, B. Set the fox to watch the geese: Voluntary IP regimes in piratical file-sharing communities. In Piracy: Leakages from Modernity; Martin Fredriksson, M., Arvanitakis, J., Eds.; Litwin Books: CA, USA, 2014; pp. 177-194.

70. Pappalardo, K.; Meese, J. In support of tolerated use: Rethinking harms, moral rights and remedies in Aus-tralian copyright law. Univ. New South Wales Law J. 2019, 42, 928-952. 